NOTE

\title{
Treatment of chytridiomycosis with reduced-dose itraconazole
}

\author{
Megan E. B. Jones ${ }^{1,4}$, David Paddock ${ }^{2}$, Lee Bender ${ }^{2}$, Jack L. Allen ${ }^{3}$, \\ Mark D. Schrenzel ${ }^{1}$, Allan P. Pessier ${ }^{1, *}$ \\ ${ }^{1}$ Amphibian Disease Laboratory, Wildlife Disease Laboratories, Institute for Conservation Research, San Diego Zoo Global, \\ San Diego, California 92112, USA \\ ${ }^{2}$ Saratoga National Fish Hatchery, United States Fish and Wildlife Service, Saratoga, Wyoming 82331, USA \\ ${ }^{3}$ Paul Harter Veterinary Medical Center, San Diego Zoo Safari Park, Escondido, California 92027, USA \\ ${ }^{4}$ Present address: Department of Pathology, College of Veterinary Medicine, University of Georgia, 501 D. W. Brooks Drive, \\ Athens, Georgia 30602, USA
}

\begin{abstract}
Effective treatment methods to eliminate infection with Batrachochytrium dendrobatidis $(B d)$ are required for development of sustainable captive survival assurance populations of amphibians and to reduce the risk of introducing $B d$ to new locations as part of amphibian trade or reintroduction programs. Treatment with itraconazole baths at $100 \mathrm{mg} \mathrm{l}^{-1}$ is commonly used in captive amphibians, but side effects are observed in some amphibian species and life stages. Naturally occurring outbreaks of chytridiomycosis in Wyoming toads Anaxyrus baxteri and White's tree frogs Litoria caerulea were treated with lower-dose itraconazole baths (e.g. $50 \mathrm{mg} \mathrm{l}^{-1}$ for White's tree frogs) and followed post-treatment with serial Taqman PCR testing to confirm elimination of $B d$ infection. Post-treatment PCR tests were consistently negative for the presence of $B d$ and treatment was deemed successful. Although this was not a controlled clinical trial, results suggest that lower doses of itraconazole may be effective for treatment of chytridiomycosis with resulting cost savings to amphibian conservation programs and a potential for a reduction in doserelated side effects from itraconazole treatment. Prospective clinical trials of alternative itraconazole treatment protocols are encouraged.
\end{abstract}

KEY WORDS: Batrachochytrium dendrobatidis $\cdot$ Wyoming toad $\cdot$ Anaxyrus baxteri $\cdot$ White's tree frog $\cdot$ Litoria caerulea

Resale or republication not permitted without written consent of the publisher

\section{INTRODUCTION}

The fungus Batrachochytrium dendrobatidis $(B d)$ causes the disease chytridiomycosis, implicated as a contributor to global amphibian population declines (Skerratt et al. 2007). Population declines due to chytridiomycosis occur rapidly, and measures to mitigate these effects in wild populations have not been introduced (Lips et al. 2006). As a result, there are efforts to develop rescue programs at sites of $B d$-associated mortality events and to establish captive survival assurance populations of amphibians with the hope of later reintroducing species to the wild (Mendelson et al. 2006, Gagliardo et al. 2008). Success of survival assurance populations requires safe, effective and practical treatments to eliminate $B d$ infection, reduce the impact of chytridiomycosis on captive amphibians and pre- 
vent movement of $B d$ to new locations as the result of translocation and reintroduction programs. The recent listing of $B d$ as a pathogen notifiable to the World Organization for Animal Health (OIE) will increase the need for reliable treatments to clear amphibians of infection for purposes of international shipment (Schloegel et al. 2010).

Treatment methods for $B d$ infection have recently been reviewed (Berger et al. 2010, Pessier \& Mendelson 2010) and include elevated temperature (Woodhams et al. 2003, Chatfield \& RichardsZawacki 2011), formalin-malachite green (Parker et al. 2002), chloramphenicol (Bishop et al. 2009) and the azole-type antifungal drugs itraconazole, fluconazole and voriconazole (Martel et al. 2011). An empirically derived treatment protocol using itraconazole applied daily as a $100 \mathrm{mg} \mathrm{l}^{-1}$ bath (Nichols et al. 2000) has been widely adapted for treatment of chytridiomycosis in captive amphibians (Forzán et al. 2008, Gagliardo et al. 2008, Pessier 2008, Tamukai et al. 2011). Advantages of this protocol are that it is well tolerated by many amphibian species and only a short daily treatment period of 5 to $10 \mathrm{~min}$ is needed. Disadvantages include the high cost of treatment and reports of treatment-associated deaths in some species or life stages (Pessier \& Mendelson 2010). There are no controlled clinical trials of itraconazole treatment in post-metamorphic amphibians and evaluations of treatment efficacy have mostly been limited to observation of clinical improvement or rely on insensitive methods to detect $B d$ infection (e.g. histology). A single report

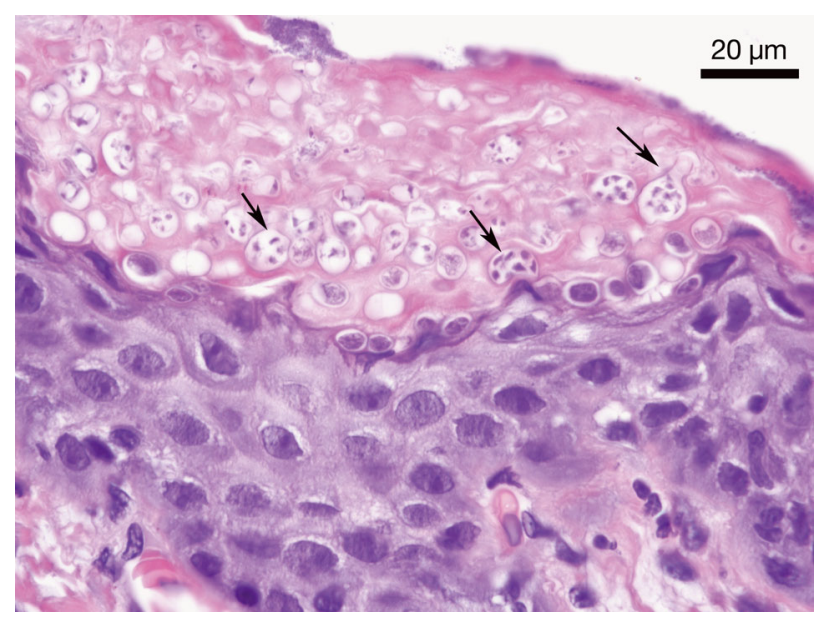

Fig. 1. Anaxyrus baxteri. Histologic section of skin from a Wyoming toad with chytridiomycosis (stained with hematoxylin and eosin), showing severe epidermal hyperplasia: hyperkeratosis and the stratum corneum contains myriad thalli typical of Batrachochytrium dendrobatidis (arrows) using the more sensitive PCR test to detect evidence of residual $B d$ infection after treatment examined only a small number of animals (Tamukai et al. 2011).

Many treatment methods for chytridiomycosis have disadvantages such as the inability of some species to tolerate elevated temperatures or toxicity concerns; therefore, further investigation on the use of drugs such as itraconazole is warranted. Reasoning that reducing the itraconazole dose could lower the risk for treatment side-effects while also reducing the cost of treatment, and encouraged by successful elimination of experimental $B d$ infection in tadpoles with minute doses of itraconazole (Garner et al. 2009), we used alternative dosing protocols of itraconazole to treat outbreaks of chytridiomycosis in 2 groups of captive anurans. Treated animals were followed after treatment by serial PCR testing to confirm elimination of $B d$ infection.

\section{MATERIALS AND METHODS}

\section{Case history: Wyoming toads}

The first outbreak occurred in a survival assurance population of 90 Wyoming toads Anaxyrus baxteri. In November 2009, there was an increase in toad deaths (10 animals over a 3-wk period) and formalin-fixed carcasses were submitted for histopathology. Histologic examination demonstrated severe epidermal hyperplasia and hyperkeratosis with myriad fungal thalli typical of $B d$ in 9 out of 10 toads (Fig. 1); a diagnosis of chytridiomycosis was made. The tenth animal had no histologic evidence of $B d$ infection and died of chronic kidney disease.

After diagnosis, treatment with itraconazole was initiated in the remaining 80 toads on 15 December 2009. Prior to treatment, samples for TaqMan PCR (see methods below) were collected from 46 of 80 animals, including at least 1 animal from each tank in the facility. Beginning 2 wk after cessation of treatment, all surviving animals were tested at 1-mo intervals for 5 mo. Each individual animal was tested on a single swab for the first 2 post-treatment tests whereas the later 3 tests consisted of pooled samples.

The treatment protocol used a commercial oral itraconazole solution (Sporanox Oral Solution, Janssen Pharmaceutica; $10 \mathrm{mg} \mathrm{ml}^{-1}$ ) diluted in distilled water and administered via a shallow bath for 5 min daily for $10 \mathrm{~d}$. The treatment solution was diluted to $100 \mathrm{mg} \mathrm{l}^{-1}$ for the first $3 \mathrm{~d}$, followed by $5 \mathrm{mg} \mathrm{l}^{-1}$ for $6 \mathrm{~d}$ 
and $50 \mathrm{mg} \mathrm{l}^{-1}$ for the last day. The inconsistent dosing schedule was the result of a communication error. After each treatment, animals were not rinsed and were placed into a freshly disinfected enclosure. Enclosures used during the treatment period were plastic tubs cleaned to remove organic waste, disinfected with diluted household bleach $(0.018 \%$ sodium hypochlorite) for a minimum of $60 \mathrm{~min}$, rinsed thoroughly with water and then allowed to dry completely for $24 \mathrm{~h}$. Animals that died during treatment were preserved in $10 \%$ neutral buffered formalin and submitted for histopathology.

\section{Case history: White's tree frogs and African bullfrogs}

The second outbreak occurred in a group of 17 White's tree frogs Litoria caerulea housed in a room with 2 African bullfrogs Pyxicephalus adspersus. In January 2010, 6 White's tree frogs died unexpectedly. Histologic examination of dead animals revealed severe epidermal hyperplasia and hyperkeratosis with myriad fungal thalli typical of $B d_{i}$ a diagnosis of chytridiomycosis was made. Other necropsy findings included pneumonia and coelomitis associated with pigmented fungi (phaeohyphomycosis) in 1 of 6 frogs, acute renal tubular degeneration $(2 / 6)$ and tissue migration of larval nematodes (1/6).

After diagnosis, treatment was initiated with itraconazole in the remaining 11 White's tree frogs and 2 African bullfrogs. Prior to treatment, samples for TaqMan PCR (see methods below) were collected from all animals. Subsequently, beginning 2 wk after cessation of treatment, surviving animals were tested at 2-wk intervals for a total of 4 times over $8 \mathrm{wk}$. Testing was repeated in February 2011, 13 mo after cessation of treatment.

The treatment protocol used a commercial oral itraconazole solution (Sporanox Oral Solution, Janssen Pharmaceutica; $10 \mathrm{mg} \mathrm{ml}^{-1}$ ) diluted in amphibian Ringer's solution and administered via a shallow bath for 5 min daily for $10 \mathrm{~d}$. The treatment solution was prepared daily and diluted to $50 \mathrm{mg} \mathrm{l}^{-1}$ for the entirety of the treatment course. After each treatment, animals were not rinsed and were placed into a new enclosure previously disinfected with $0.4 \%$ sodium hypochlorite (a 1:10 dilution of household bleach) for a minimum of 60 min contact time, thoroughly rinsed with water, and allowed to dry completely for $24 \mathrm{~h}$. Animals that died during treatment were preserved in $10 \%$ neutral buffered formalin and submitted for necropsy and histopathology.

\section{Taqman PCR for Bd}

Samples for Taqman PCR were collected using a swabbing protocol that includes the ventral skin surfaces of the abdomen, legs and feet (Pessier \& Mendelson 2010). Pooled samples in Wyoming toads used the same swab to sample 3 to 4 different toads from the same enclosure. Samples were collected on rayon-tipped, plastic-handled swabs (Dryswab ${ }^{\mathrm{TM}}$ Fine Tip MW113, Advantage Bundling SP/Medical Wire and Equipment). Briefly, Taqman PCR generally followed the method, primers and probe of Boyle et al. (2004) and Hyatt et al. (2007), including preparation of DNA template with Prepman Ultra ${ }^{\circledR}$ (Applied Biosystems) and the use of an exogenous internal positive control labeled with VIC ${ }^{\text {TM }}$ (Applied Biosystems) for each sample to detect PCR inhibitors. Reactions used the Taqman Environmental Mastermix 2.0 (Applied Biosystems). Assays were run in triplicate on an ABI/Applied Biosystems 7900HT thermocycler using 384-well plates. Samples that amplified at a threshold cycle $\left(C_{\mathrm{t}}\right) \geq 50$ were considered negative. Samples amplifying at a $C_{\mathrm{t}}$ of $<50$ in 2 or more wells were considered positive. Quantification standards were created by growing $B d$ isolate JEL 197 on $1 \%$ tryptone agar and zoospores were harvested by rinsing plates with $1 \times$ phosphate buffered saline. After collection, zoospores were counted 3 times on a hemocytometer to determine a range of zoospores $\mathrm{ml}^{-1}$. Standard curves were generated with 10-fold serial dilutions (range: $1 \times 10^{6}$ to $1 \times 10^{-2}$ zoospores $\mathrm{ml}^{-1}$ ). In addition to positive controls (quantification standards), each plate included a negative control (Taqman mastermix and no sample DNA) as well as 4 positive and negative quality assurance controls consisting of swabs either inoculated with $B d$ zoospores or sham-inoculated, respectively. The intensity of infection in positive samples was expressed as the number of zoospore equivalents per swab (Vredenburg et al. 2010).

\section{RESULTS}

\section{Wyoming toads}

Taqman PCR was positive from 32 of $46(69.5 \%)$ pre-treatment skin swab samples. Of the 32 PCRpositive animals, $13(41 \%)$ had $<300$ zoospore equivalents per swab (range: 7-274), 4 (12.5\%) had between 2000 and 6000 zoospore equivalents per swab (range: 2107-5491), 5 (15.6\%) had between 10000 and 40000 zoospore equivalents per swab (range: 
10935 to 38794$)$ and 10 (31\%) had >50 000 zoospore equivalents per swab (range: 67906 to 1010590 ). Post-treatment PCR tests of surviving animals on 5 occasions over a 5-mo period were consistently negative, meaning that no $B d$ DNA was detected (Table 1).

During the 10-d treatment period, $15(19 \%)$ of the 80 treated toads died. Of the dead toads, $14(93 \%)$ died within the first $6 \mathrm{~d}$ of treatment (Day 1, $\mathrm{n}=1$; Day 2, $\mathrm{n}=1$; Day 3, $\mathrm{n}=3$; Day $4, \mathrm{n}=4$; Day $6, \mathrm{n}=5$; and Day $8, \mathrm{n}=1$ ). Pre-treatment skin swab samples for PCR were available from 8 of the 15 animals that died during treatment. Of these toads, 7 (87.5\%) had $>50000$ zoospore equivalents per swab and 1 $(12.5 \%)$ had 5491 zoospore equivalents per swab. Of the 5 toads with between 10000 and 40000 zoospore equivalents per swab, all $(100 \%)$ survived the treatment period and of the 10 toads with $>50000$ zoospore equivalents per swab, only $3(30 \%)$ survived the treatment period.

On necropsy examination of toads that died during the treatment period, 14 (93\%) of 15 had moderate to severe histologic lesions of chytridiomycosis similar to those observed in animals that died prior to treatment. The single toad without evidence of chytridiomycosis died on Day 4 of treatment and histologic examination revealed severe chronic renal disease (glomerulosclerosis and interstitial fibrosis). Other findings on the histopathology of toads that died during the treatment period included acute pneumonia (5/15), bacterial septicemia (2/15) and mild membranous glomerulopathy $(6 / 15)$.

\section{White's tree frogs}

Taqman PCR was positive from 6 (45\%) of 11 pretreatment skin swabs obtained from White's tree frogs and in both $(100 \%)$ of the African bullfrogs. Of

Table 1. Outbreak 1. Summary of real-time Taqman PCR tests for Batrachochytrium dendrobatidis performed on a captive colony of Wyoming toads Anaxyrus baxteri during and after an outbreak of chytridiomycosis. Animals were treated with itraconazole between 15 and 24 December 2009

\begin{tabular}{|lccc|}
\hline Date $(\mathrm{mo} / \mathrm{d} / \mathrm{yr})$ & No. tested & No. positive & $\%$ positive \\
\hline $12 / 15 / 2009$ & 46 & 32 & 69.5 \\
$1 / 10 / 2010$ & 79 & 0 & 0 \\
$2 / 11 / 2010$ & 78 & 0 & 0 \\
$3 / 11 / 2010$ & 78 pooled (25 swabs) & 0 & 0 \\
$4 / 14 / 2010$ & 78 pooled (24 swabs) & 0 & 0 \\
$5 / 23 / 2010$ & 74 pooled (21 swabs) & 0 & 0 \\
\hline
\end{tabular}

the PCR-positive White's tree frogs, a single animal had 83040 zoospore equivalents per swab and the remaining 5 positive frogs all had $<100$ zoospore equivalents per swab (range: 2.5 to 51 ). The 2 African bullfrogs had 38 and 94859 zoospore equivalents per swab. Post-treatment PCR tests of surviving animals were consistently negative (no $B d$ DNA detected) on 4 occasions over a 2 -mo period and on a single occasion 13 mo after cessation of treatment (Table 2).

During the 10-d treatment period, a single White's tree frog died on the ninth treatment day. The other 10 White's tree frogs and both African bullfrogs survived. The White's tree frog that died had the highest infection intensity in pre-treatment testing (83040 zoospore equivalents per swab). On necropsy examination, there was histiocytic inflammation in multiple tissues with intralesional bacteria, and bacterial septicemia was the likely cause of death. Histologic examination of the skin demonstrated moderate epidermal hyperplasia and hyperkeratosis; however, no remaining thalli of $B d$ were identified.

\section{DISCUSSION}

In these outbreaks of naturally occurring chytridiomycosis, treatment with itraconazole baths was associated with elimination of $B d$ infection in animals that survived the treatment period. The itraconazole concentrations used for the White's tree frog treatments and for most of the Wyoming toad treatments were significantly lower than the $100 \mathrm{mg}$ $1^{-1}$ dose widely used in captive amphibians. Because the $100 \mathrm{mg} \mathrm{l}^{-1}$ dose was empirically derived in the original treatment report (Nichols et al. 2000) and because very low doses appear to be effective in tadpoles (Garner et al. 2009), our observations suggest that further evaluation of reduced-dose itraconazole treatment protocols is warranted. The Wyoming toads did receive the standard $100 \mathrm{mg} \mathrm{l}^{-1}$

Table 2. Outbreak 2. Summary of real-time Taqman PCR tests for Batrachochytrium dendrobatidis performed on a captive colony of White's tree frogs Litoria caerulea during and after an outbreak of chytridiomycosis. Animals were treated with itraconazole between 13 and 22 January 2010

\begin{tabular}{|lccc|}
\hline Date $(\mathrm{mo} / \mathrm{d} / \mathrm{yr})$ & No. tested & No. positive & $\%$ positive \\
\hline $1 / 13 / 2010$ & 11 & 5 & 45 \\
$2 / 8 / 2010$ & 10 & 0 & 0 \\
$2 / 12 / 2010$ & 10 & 0 & 0 \\
$2 / 22 / 2010$ & 10 & 0 & 0 \\
$3 / 10 / 2010$ & 10 & 0 & 0 \\
\hline
\end{tabular}


itraconazole dose for the first $3 \mathrm{~d}$ of treatment, and it is possible that this dose alone was responsible for any beneficial effects of itraconazole. A weakness of our report is that a controlled clinical trial could not be performed (Berger et al. 2010). In a controlled trial, the ability would exist to compare elimination of $B d$ from itraconazole-treated infected animals as well as untreated infected animals, and therefore definitively distinguish treatment-associated clearance of infection from spontaneous treatment-independent clearance of infection. However, we consider spontaneous clearance of $B d$ infection unlikely because both Wyoming toads and White's tree frogs are very susceptible to lethal $B d$ infection (Jennings et al. 2001, Voyles et al. 2009) and because 8 (53\%) of 15 treated Wyoming toads that had very likely lethal infection intensities of $>10000$ zoospore equivalents per swab (>10000 zoospore equivalents per swab is associated with declines of Rana muscosa; see Vredenburg et al. 2010) survived treatment and became $B d$-negative during serial posttreatment PCR testing.

Several deaths occurred in Wyoming toads during the first $6 \mathrm{~d}$ of treatment; however, most of these animals had the highest $B d$ infection intensities - over 50000 zoospore equivalents per swab - and severe skin lesions consistent with lethal chytridiomycosis were observed on histologic examination of the skin. Many also had concurrent medical conditions such as bacterial pneumonia or chronic kidney disease (predating itraconazole treatment), which are likely to have affected survival. These observations suggest that very high infection intensities and confounding factors such as concurrent medical conditions should be considered when evaluating success or failure of treatment protocols. We cannot exclude the possibility that itraconazole treatment may have contributed to the deaths of some toads with the very highest infection intensities, and this question can only be answered in a prospective experimental trial. Finally, severe chytridiomycosis results in hyponatremia and hypokalemia (Voyles et al. 2009), and these potentially lethal disturbances in electrolyte balance were not addressed in the treatment protocol for Wyoming toads. Supportive treatments of electrolyte replacement as well as antibiotics for secondary bacterial infection have been suggested for animals severely ill with chytridiomycosis, and perhaps could have improved the treatment outcome (Berger et al. 2010, Pessier \& Mendelson 2010).

This clinical report is unique because clearance of $B d$ infection was documented by repeated PCR tests over several months of post-treatment monitoring.
Despite the ability of available PCR techniques to detect very small amounts of $B d$ DNA, false-negative tests do occur in individual animals with very light (low intensity) $B d$ infections. One proposed strategy to increase confidence that individual animals are truly negative for $B d$ is to obtain 3 separate PCR samples over a 14-d period (Hyatt et al. 2007). Because low-intensity $B d$ infections are a possible outcome following an unsuccessful antifungal treatment regime, the use of multiple post-treatment PCR tests has been advocated for evaluation of $B d$ treatment success in clinical trials (Berger et al. 2010). The extent of post-treatment PCR monitoring described in this report is impractical or cost-prohibitive for most amphibian programs, but the examples are useful for an initial evaluation of lower-dose itraconazole treatment regimes.

We hope that these case studies will encourage examination of low-dose or alternative itraconazole protocols in prospective experimental trials of treatment methods for $B d$ infection. Studies that may be of interest include determination of the lowest effective dose, the number of days required for successful treatment, the value of adjunct treatments such as electrolyte supplementation and, if treatment improves or worsens, clinical outcome for animals with very high-intensity $B d$ infection.

While awaiting the results of experimental trials, the use of reduced-dose itraconazole could be considered for the empirical treatment of $B d$-infected amphibians. Use of a $50 \mathrm{mg} \mathrm{l}^{-1}$ dose could double the number of animals treated with a single bottle of the commercially available oral itraconazole solution and this cost savings would be especially valuable for amphibian rescue programs that often rely on donated supplies (Gagliardo et al. 2008). Furthermore, a lower itraconazole dose might reduce the risk of dose-related adverse reactions to either itraconazole itself or to the solvents used to manufacture the commercially available itraconazole solution. The decision to use a reduced-dose itraconazole treatment protocol should be carefully considered by the attending veterinarian, recognizing that almost all of the treatment methods for chytridiomycosis proposed to date have shown inconsistent results in terms of efficacy or safety (Woodhams et al. 2012). Our suggestions for the application and evaluation of itraconazole treatments are based on our experiences described in this report and from a consensus of amphibian veterinarians attending a 2009 amphibian disease workshop at the San Diego Zoo (Pessier \& Mendelson 2010). Briefly, these include: 
(1) Treatment with itraconazole even at a reduced dose may not be tolerated or effective in all amphibian species or life stages (e.g. tadpole, juvenile and adult). If there is no prior experience with the use of itraconazole in a particular species or life stage, treatment should first be tried on a small number of animals to evaluate safety before treating a larger group. Treatment should be halted if unexpected numbers of deaths occur during treatment, remembering that some mortality may be expected for animals severely ill with chytridiomycosis.

(2) Itraconazole baths using either the $50 \mathrm{mg} \mathrm{l}^{-1}$ reduced dose or the standard $100 \mathrm{mg} \mathrm{l}^{-1}$ dose are applied as a 5-min daily bath for 10 consecutive days. Baths should be agitated to ensure that treatment solution reaches all skin surfaces and animals should be returned to a $B d$-free enclosure each day. Preparing the itraconazole baths in an electrolyte solution such as amphibian Ringer's is suggested. However, it should be recognized that all factors such as length of daily baths, duration of treatment, the use of electrolyte solutions and a decision whether to rinse residual itraconazole from the skin of animals after treatment are empirically derived and determination of their importance or benefit awaits experimental trials.

(3) If possible, the efficacy of treatment should be evaluated by post-treatment PCR testing. This testing should begin at $2 \mathrm{wk}$ or more after the last treatment application to allow for shedding of dead $B d$ organisms that could still result in a positive PCR test or in the case of a treatment failure, allow the remaining viable organisms to proliferate to levels detectable by PCR. The use of multiple post-treatment PCR tests may increase confidence in negative post-treatment test results. The development of optimal post-treatment testing protocols could be the subject of additional experimental trials.

Acknowledgements. The authors thank I. Navarrete, T. Tucker, K. Benson, J. Burchell and Y. Cates for outstanding PCR, database and histology support. J. Longcore kindly provided $B d$ isolate JEL 197 used to generate PCR standards. This project was supported by National Leadership Program grant LG-25-08-0066 from the Institute for Museum and Library Services. Any views, findings, conclusions or recommendations expressed in this publication do not necessarily represent those of the Institute of Museum and Library Services.

\section{LITERATURE CITED}

Berger L, Speare R, Pessier A, Voyles J, Skerratt LF (2010) Treatment of chytridiomycosis requires urgent clinical trials. Dis Aquat Org 92:165-174
Bishop PJ, Speare R, Poulter R, Butler M and others (2009) Elimination of the amphibian chytrid fungus Batrachochytrium dendrobatidis by Archey's frog Leiopelma archeyi. Dis Aquat Org 84:9-15

> Boyle DG, Boyle DB, Olsen V, Morgan JAT, Hyatt AD (2004) Rapid quantitative detection of chytridiomycosis (Batrachochytrium dendrobatidis) in amphibian samples using real-time Taqman PCR assay. Dis Aquat Org 60:141-148

> Chatfield MWH, Richards-Zawacki CL (2011) Elevated temperature as a treatment for Batrachochytrium dendrobatidis infection in captive frogs. Dis Aquat Org 94:235-238

> Forzán MJ, Gunn H, Scott P (2008) Chytridiomycosis in an aquarium collection of frogs: diagnosis, treatment and control. J Zoo Wildl Med 39:406-411

> Gagliardo R, Crump P, Griffiths E, Mendelson JR, Ross H, Zippel KC (2008) The principles of rapid response for amphibian conservation using the programmes in Panama as an example. Int Zoo Yearb 42:125-135

Garner TWJ, Garcia G, Carroll B, Fisher MC (2009) Using itraconazole to clear Batrachochytrium dendrobatidis infection and subsequent depigmentation of Alytes muletensis tadpoles. Dis Aquat Org 83:257-260

> Hyatt AD, Boyle DG, Olsen V, Boyle DB and others (2007) Diagnostic assays and sampling protocols for the detection of Batrachochytrium dendrobatidis. Dis Aquat Org 73:175-192

Jennings MR, Beiswinger R, Corn S, Parker M and others (2001) Population and habitat viability assessment for the Wyoming Toad (Bufo baxteri). Final workshop report. IUCN/SSC Conservation Breeding Specialist Group, Apple Valley, MN

> Lips KR, Brem F, Brenes R, Reeve JD and others (2006) Emerging infectious disease and the loss of biodiversity in a neotropical amphibian community. Proc Natl Acad Sci USA 103:3165-3170

- Martel A, Van Rooij P, Vercauteren G, Baert K and others (2011) Developing a safe antifungal treatment protocol to eliminate Batrachochytrium dendrobatidis from amphibians. Med Mycol 49:143-149

Mendelson JR, Lips KR, Gagliaro RW, Rabb GB and others (2006) Confronting amphibian declines and extinctions. Science 313:48

Nichols DK, Lamirande EW, Pessier AP, Longcore JE (2000) Experimental transmission and treatment of cutaneous chytridiomycosis in poison dart frogs (Dendrobates auratus and Dendrobates tinctorius). In: Baer CK, Patterson RA (eds) Proceedings of the American Association of Zoo Veterinarians (AAZV) and International Association for Aquatic Animal Medicine Joint Conference, New Orleans, LA, 1-21 Sep 2000. AAZV, Yulee, FL, p 42-44

> Parker JM, Mikaelian I, Hahn N, Diggs HE (2002) Clinical diagnosis and treatment of epidermal chytridiomycosis in African clawed frogs (Xenopus tropicalis). Comp Med 52:265-268

> Pessier AP (2008) Management of disease as a threat to amphibian conservation. Int Zoo Yearb 42:30-39

Pessier AP, Mendelson JR (2010) A manual for control of infectious diseases in amphibian survival assurance colonies and reintroduction programs. IUCN/SSC Conservation Breeding Specialist Group, Apple Valley, MN

> Schloegel LM, Daszak P, Cunningham AA, Speare R, Hill B (2010) Two amphibian diseases, chytridiomycosis and ranaviral disease, are now globally notifiable to the World Organization for Animal Health (OIE): an assessment. Dis Aquat Org 92:101-108 
Skerratt LF, Berger L, Speare R, Cashins S and others (2007) Spread of chytridiomycosis has caused the rapid global decline and extinctions of frogs. EcoHealth 4:125-134

Tamukai K, Une Y, Tominaga A, Suzuki K, Goka K (2011) Treatment of spontaneous chytridiomycosis in captive amphibians using itraconazole. J Vet Med Sci 73: 155-159

Voyles J, Young S, Berger L, Campbell C and others (2009) Pathogenesis of chytridiomycosis, the cause of catastrophic amphibian declines. Science 326:582-585

Vredenburg VT, Knapp RA, Tunstall TS, Briggs C (2010)

Editorial responsibility: Cynthia Carey,

Boulder, Colorado, USA
Dynamics of an emerging disease drive large scale amphibian population extinctions. Proc Natl Acad Sci USA 107:9689-9694

Woodhams DC, Alford RA, Marantelli G (2003) Emerging disease of amphibians cured by elevated body temperature. Dis Aquat Org 55:65-67

> Woodhams DC, Geiger CC, Reinert LK, Rollins-Smith LA, and others (2012) Treatment of amphibians infected with chytrid fungus: learning from failed trials with itraconazole, antimicrobial peptides, bacteria and heat therapy. Dis Aquat Org 98:11-25

Submitted: December 21, 2011; Accepted: March 29, 2012 Proofs received from author(s): June 20, 2012 